\title{
Using Interactive Picture-Book Read-Alouds with Middle School EFL Students
}

\author{
Chia-Ho Sun $^{1}$ \\ ${ }^{1}$ Department of Applied English, Kainan University, Taiwan \\ Correspondence: Chia-Ho Sun, Department of Applied English, Kainan University, Taoyuan City, Taiwan. \\ E-mail: chiaho.iub@gmail.com
}

Received: June 2, 2020

Accepted: June 27, 2020

Online Published: June 28, 2020

doi: $10.5539 /$ elt.v13n7p130

URL: https://doi.org/10.5539/elt.v13n7p130

\begin{abstract}
The current study investigated the effects of interactive picture-book read-alouds on middle school EFL students' word inference ability and attitudes toward reading in English. To this end, two classes of seventh-grade students from a public middle school in Taiwan participated and were randomly divided into two groups: an interactive picture-book read-aloud (IPBRA) group and a control group. The intervention took place in a 40-minute morning study hall per week over a period of 10 weeks. The two groups were tested using Reading Attitude Survey (RAS) and Word Inference Assessment (WIA) two weeks before and then two weeks after the intervention was implemented to assess improvement. Results indicated that interactive picture-book read-alouds had a positive impact on EFL middle schoolers' reading attitudes and use of text and prior knowledge to infer the meanings of unfamiliar words. This study suggests that the motivating learning atmosphere of interactive picture-book read-alouds provided positive classroom environment and enabled students to have fun while interacting freely with one another, which, in turn, facilitated reading attitude changes, leading to better learning and better performance on word inference in subsequent reading activities.
\end{abstract}

Keywords: read-alouds, reading attitude, word inference ability, middle school students

\section{Introduction}

Often when English teachers announce reading time, young students past the elementary grades mutter and make faces. First language (L1) students' reading attitudes were observed to become more negative gradually throughout the elementary and then middle school years (McKenna et al., 2012; McKenna, Kear, \& Ellsworth, 1995). Middle school students have often been characterized as apathetic readers (Warren, 2012). This trend of negative attitudes toward recreational and academic reading was also found among teenage learners in English as a foreign language (EFL) contexts (Chen \& Chen, 2015). My own survey of 687 eighth graders in Taiwan (365 in 2017 and 322 in 2018), for example, showed that only $2 \%$ often (once every 1-2 weeks) did outside reading in English, $5 \%$ sometimes (once every 1-2 months), $48 \%$ seldom (once or twice every year), and $45 \%$ never. When asked, these middle school students claimed that English texts written for native speakers at their age level were too difficult and that the laborious task of looking up unfamiliar words in the dictionary led to prolonged reading time, which wore down their reading interests. For them, reading in English was tiring, a waste of time, and unrewarding work. Accordingly, they became reluctant readers.

A more efficient and meaningful way for readers to deal with unfamiliar vocabulary without interrupting the flow of reading is to infer meaning from context (Nation, 2001). As specified in the Taiwan Ministry of Education's (MOE) Grade 1-9 Curriculum Guidelines of English teaching and learning, middle school students should acquire the ability to infer meaning from picture and context cues before they enter secondary school (MOE, 2008). However, the survey results mentioned earlier suggested that sole reliance on textbooks did not seem to provide sufficient resources for middle school students to learn from context. This problem led me to the question, what English reading instructional approach would offer these middle school learners sustained, engaging reading experiences that would enhance their ability to gather clues from the context to crack the meaning of unknown vocabulary and further improve their attitudes toward reading? 


\section{Literature Review}

Just as reading aloud to children has long been valued as a way to strengthen their positive attitudes toward reading and foster their desire to read independently (Trelease, 2006), scholars have also promoted reading aloud to older learners to enhance comprehension of the text (Ariail \& Albright, 2005); foster interest, engagement, and motivation (Albright \& Ariail, 2005); and encourage the love of reading (Sanacore, 2000). Older learners from middle school to college have been found to enjoy being read to by their teachers (Artley, 1975; Khodabakhshi \& Lagos, 1993; Livaudais, 1985), especially middle school students. For example, Ivey and Broaddus (2001) surveyed 1,765 sixth-grade students and found that these students rated teacher read-aloud as one of their two most favorite reading activities in school because it helped make texts more comprehensible and/or more interesting to them. Likewise, Clark and Andreasen (2014) found that regardless of their reading attitudes, middle school students enjoyed being read to by teachers. In particular, students with more negative attitudes liked the relaxed classroom setting with less pressure to perform. Clark and Andreasen concluded that teacher read-aloud practices motivated reluctant readers and supported their vocabulary learning.

\subsection{Read-Alouds and Attitudes toward Reading}

Although middle school students with negative attitudes toward reading identified teacher read-aloud practices as enjoyable and motivating (Clark \& Andreasen, 2014), there is a paucity of research into reluctant readers' changes in reading attitudes after experiencing teacher read-alouds. Working with Arabic-speaking intermediate school students, Amer (1997) found that EFL students who read silently while the teacher read aloud showed significantly better understanding than students who read silently alone and further developed more positive attitudes toward reading. Hilbelink's (1998) study, on the other hand, reported that a teacher's reading juvenile books aloud to eighth-grade students did not result in significant changes in their attitudes toward reading. Santos (1987) also found no significant changes in middle-school Spanish-speaking EFL learners' attitudes after ten weeks of hearing a children's novel read-aloud, though the attitude score of learners who received read-aloud sessions improved while those of the control group declined. In a study of 145 students in grades six through eight at two schools, Lyman (2010) investigated changes in reading attitudes when teachers read aloud 24 picture books, each time introducing the book title, author, and illustrator, and encouraged discussion with questions to arouse interest and activate background knowledge and prior experiences prior to, during, and after reading aloud. Although statistically significant changes in reading attitudes were found only among sixth graders in one school and seventh graders in the other school, Lyman claimed that the qualitative data gathered from Rhody Secondary Reading Attitude Assessment (RSRAA) demonstrated that reading picture books to middle school students had a positive impact on their reading attitudes. However, as the RSRAA was designed to quantitatively measure attitudes toward reading using a 5-point Likert scale (Tullock-Rhody \& Alexander, 1980), Lyman's qualitative claims are questionable. Moreover, no control group was used in her study, further weakening the argument that picture-book read-alouds could improve middle graders' reading attitudes.

\subsection{Picture Books with Older Learners}

Johnson (2002) contended that picture books provide "one of the best read-aloud resources for teachers of all ages" (p. 1), a position echoed by Trelease (2006), who declared that even teenagers appreciate good picture books. Zambo (2005) also observed that many picture books now deal with sophisticated, mature issues speaking directly to the concerns and life experiences of older learners. They are a rich source of high-interest, easily accessible reading materials for middle school students with lower reading proficiency. The combination of narratives and illustrations is contextually whole and inherently meaningful (Smallwood, 1992), so readers remain actively engaged in figuring out the meanings of unfamiliar words/concepts to grasp themes and big ideas (Harvey \& Goudvis, 2017). Through conversations and observations, Beers (1998) found that alliterate middle school students preferred books with many illustrations because the illustrations helped them bridge the gap between print and meaning. Sun (2015) also confirmed that integrating picture book lessons into EFL reading instruction can facilitate older learners' word learning. Similarly, Hibbing and Rankin-Erickson (2003) asserted that illustrations pictured in a text helped reluctant middle school readers with limited vocabulary "in understanding what they read and [served] as vehicles to provide additional and supporting information" (p. 765), and that by making reading more enjoyable for reluctant readers, illustrations encouraged more positive attitudes toward reading.

\subsection{Inferring Word Meanings from Context}

For older learners, who are expected to read texts of increasing complexity, neither teacher elaboration of words in context nor direct word-meaning explanation meets their need for rapid vocabulary growth (Stahl \& Nagy, 2005), much less memorizing lists of words (Stoller \& Grabe, 1993). Using context to derive meaning, in 
contrast, is a powerful way to increase vocabulary (Walters, 2004). Thus, developing the skill of drawing inferences from context is of need for older learners (Nation, 2001).

Carnine, Kameenui, and Coyle (1984), for example, compared the effects of three conditions, rule-plus-practice, practice-only, and no intervention, on fourth-, fifth-, and sixth-graders' ability to infer meaning from context. In the rule-plus-practice group, students were told to read training passages keeping in mind the rule, "When there's a hard word in a sentence, look for other words in the story that tell you more about that word" (p. 197) and given systematic practice in applying the rule, whereas the practice-only group was given the same passages and practice without being told the rule. Both the rule-plus-practice group and the practice-only group outperformed the control group, but no difference was found between them, suggesting that explicit teaching of a general rule did not improve student performance beyond practice alone. Carnine et al. speculated that telling the practice-only group to look back at the passage while choosing an answer inadvertently advised them to use context. To separate effects of using strategies from those of practice only, Walters (2006) examined the effects of three training conditions on 44 ESL adult learners: using a general strategy, using specific context clues, and practicing with cloze exercises. Following three two-hour sessions of training, the results revealed that all three groups performed better on a post-test, with the largest improvement found in the strategy group, although the differences among the three groups were not significant. Nevertheless, only the strategy group's post-test scores were significantly higher than their pre-test scores, suggesting the effectiveness of the strategy approach over specific-context-clue instruction or practice alone.

Rather than training to use specific context clues or step-by-step strategies, Goerss, Beck, and McKeown (1999) used an interactive discussion approach that involved examining and considering context to derive word meaning information to engage fifth and sixth grade less-skilled readers in thoughtful analysis of a text. As the teacher led the students through understanding the text by probing and questioning, the emphasis was not on getting a dictionary-perfect definition but on grasping the gist of the text and obtaining enough information from the context to deal with unknown words. Seeking to create a reasonable hypothesis about word meanings, Goerss et al. asserted that the instructional task in their study provided a more realistic strategy by guiding students to derive a sense of an unfamiliar word rather than looking for one specific meaning because in actual reading situations, context might or might not provide enough information to infer meanings of unfamiliar words. After seven sessions of the intervention, students' ability to derive word meaning from context had improved dramatically. While Goerss et al.'s qualitative data supported this interactive approach to teaching word meaning inference, more robust verification is needed to show the degree to which students' word inference ability can be trained using this approach. The present study, therefore, aimed to investigate the effects of interactive picture-book read-alouds on middle school EFL students' attitudes toward reading and abilities to derive word meaning from context and illustrations.

\section{Method}

\subsection{Research Design}

The intervention took place in a 40-minute morning study hall per week over a period of 10 weeks. Totally 10 read-aloud lessons were conducted; each with a different picture book. During each lesson, as the interactive picture-book read-aloud (IPBRA) group participated in the read-aloud, the control group engaged in the regular learning activities of morning study halls such as completing English reading worksheets and taking quizzes. Two tests were administrated two weeks before the intervention as the pre-tests to assess the two groups' word inference ability and attitudes toward reading in English and again two weeks after the intervention as the post-tests. The reason why the pre- and post-tests were conducted two weeks before and after the intervention was to prevent the IPBRA group from being aware of receiving "special" instruction to lessen the likelihood of a Hawthorne effect.

\subsection{Participants}

Fifty-six seventh-grade students from two classes taught by the same English teacher in a public middle school in northern Taiwan participated in the current study. The two classes were randomly assigned to the IPBRA group (29 students) and the control group (27 students). An independent-samples $t$-test was conducted to compare the two groups' scores on an elementary-level reading exam of the General English Proficiency Test (GEPT) to ascertain that they were at equivalent levels of English reading proficiency. The average score for the IPBRA group was $52.90(S D=4.97)$ and the control group $53.70(S D=4.79)$, with no significant difference between the two groups $(t=-.617, p=.540)$. 


\subsection{Read-Aloud Materials and Target Words}

The 10 picture books used for the read-alouds were chosen based on students' interests and text readability. From the IPBRA group's responses to a picture-book-interest questionnaire (Sun, 2015), five themes/genres that they favored were identified: fractured fairy tales, being oneself, nontraditional gender roles, friendship, and homosexuality. As for text readability, the coverage of familiar words was set at $90-95 \%$ to avoid easy inferencing due to the unique feature of picture books: Pages are dominated by illustrations that also provide context for deriving the meanings of unfamiliar words (Sun, 2020). Two picture books with the designated coverage for each of the five themes/genres were selected based on the teacher's judgment of her students' vocabulary knowledge.

Five steps were involved in choosing three target words from each of the 10 picture books for modeling and practicing word inference during the read-alouds. First, the researcher set the criterion that the word should not appear in any elementary school or seventh grade English textbooks used in the district. Second, the teacher selected 5 vocabulary items from the approved list of each book based on the following three criteria: (1) most likely to be unfamiliar to her seventh graders, (2) important to understanding the text, and (3) with a meaning that could be inferred from pictures and/or context clues. Third, a pilot test of those 50 words was administrated to 30 seventh graders from another class at the same school. Fourth, words unknown to at least $99 \%$ of the students were selected: 43 words. Finally, 3 target words from each picture book were selected from the 43 words based on their relevance to students' daily experiences, that is the familiarity of the concept (Nation, 2001).

\subsection{The IPBRA Approach}

The goal of the IPBRA approach is twofold: (1) have students enjoy a good story by reading for meaning, and (2) model and hold a discussion about using context and picture clues to crack new vocabulary. Each IPBRA lesson started with a book introduction in which the teacher read its title, author, and illustrator and then showed the front and back covers and the endpapers, leading students in a conversation about personal experiences and prior knowledge in relation to the topic of the book while encouraging them to start thinking about what might happen in the book. This initial step of activating students' background knowledge aimed to engage and prepare them to listen to the story (Harvey \& Goudvis, 2017), which was vital to their comprehension of the text and unfamiliar vocabulary (Hickman, Pollard-Durodola, \& Vaughn, 2004). The teacher next read the book aloud, demonstrating how both illustrations and text contributed to the meaning of the story and various ways to construct meaning and build understanding. During the read-aloud, the teacher focused on three strategies: (1) making connections, (2) generating questions, and (3) making inferences, which she first modeled as she read aloud and then led the class in further guided and independent practice of these strategies.

To develop students' use of the strategy of making connections, the teacher, as she read the text, thought aloud, sharing her inner voice. She first showed students how to make personal and across-text connections to further understanding of the characters, problems, events, and ideas of the text and to gain greater insight into the story. She then invited students to connect the new to the known by stopping to express their thoughts, feelings, or ideas that the text called to mind, beginning with "It reminds me of ...." As the teacher read on, she encouraged students to connect the storyline, characters, and issues to their own lives and experiences, to other texts they had read, and to their neighborhood, community, country, or the world.

Generating questions was another strategy used to take students deeper into reading during the read-aloud. To demonstrate this strategy, the teacher would stop reading to ask a question when she was puzzled or confused. Then she kept reading aloud and asked students to work with her to seek out further information that answered it. Sometimes the answer to the questions was easy to find, sometimes the questions would challenge students to rethink their opinions, and sometimes the initial questions led to bigger questions that prompted further discussions or debates and kept students pondering. Students were also encouraged to wonder about the text and ask their own questions throughout the read-aloud.

The last strategy demonstrated during the read-aloud was inferential thinking. This strategy aimed to help students create interpretations, predict outcomes, figure out the meanings of unknown words, and surface themes and big ideas. As she read aloud, the teacher would make inferences about the characters' thoughts, feelings, or motives, or predict upcoming events, modeling how to merge what she had already known and her background knowledge with clues in the text and illustrations to come up with an idea that was not explicitly stated by the author. At times the teacher would also ask students to search for answers to questions she and other students had generated to extend their understanding beyond the text. Using context clues to figure out the meaning of unfamiliar words is also part of the strategy of inferring. As she read each story out loud, the teacher would draw 
attention to the three target vocabulary items. There is not a specific procedure for inferring from context that will prevent the read-aloud from becoming a training session. In fact, in this process decoding did not interfere with comprehension of the text or detract from the pleasure of being read aloud to. The intent was not for students to produce a dictionary-perfect definition, but to ascertain that they understood the context and could find clues in the text and pictures that might help them draw a reasonable hypothesis about a word's meaning (Sun, 2020). For the first target word, the teacher modeled how to figure out the meaning using four prompts: (1) What is happening? (2) How is the word being used? (3) Take what you know and gather all the context and picture clues you have that relate to the word; and (4) Think what this word might mean (Serravallo, 2015). She then invited the whole class to derive the meanings of the other two target words using the prompts, gradually handing over control to the students. During the discussion of word meanings, the teacher often provided leading questions, such as "Why do you think that?" and "How did you figure that out?" to make students' reasoning available to others (Maloch \& Beutel, 2009).

\subsection{Instruments}

Reading Attitude Survey (RAS) and Word Inference Assessment (WIA) were administrated to assess the extent to which the interactive picture-book read-alouds promoted students' attitudes toward reading in English and word inference ability, respectively.

\subsubsection{Reading Attitude Survey (RAS)}

Chiang's (2016) revised version of RAS consists of 26 statements representing reading attitudes in three domains: affective (10 statements), behavioral (9), and cognitive (7). A 4-point Likert-scale ranging from strongly disagree (1) to strongly agree (4) was employed for the students to rate how strongly they agree or disagree with each statement. Each student's overall reading attitude was measured by the sum of the averaged scores from the three domains. The Cronbach's $\alpha$ values of the three domains were $0.87,0.91$, and 0.85 , respectively, confirming that the questionnaire had high reliability.

\subsubsection{Word Inference Assessment (WIA)}

As Nation (2001) claimed, the initial appearance of the words being tested appeared in real and continuous text contexts would enhance the validity of testing format of guessing a word's meaning from context. Thus, the picture book My Lucky Day (2003) by Keiko Kasza, with a 90\% coverage, was chosen to be the test picture book. The story is a fractured fairy tale that helps readers see things from different angles and reexamine their own perspectives on the naïve pig and sly fox. The juxtaposition of the familiar and the unpredictable would hold older readers' attention and made learning a pleasure (Hill, 2002). Sun's (2020) WIA was applied to measure students' ability to use context and prior knowledge to infer word meanings. Six test words from My Lucky Day using the same procedure specified earlier were chosen to evaluate students' inferencing processes: roast (noun), struggle (verb), filthy (adjective), scrubber (noun), fatten (verb), and tender (adjective). Students' inferences for each of the six test words were scored using Sun's word inference ability rubric. The rubric is composed of four levels of word inference ability: below mastery (1 point), progressing toward mastery ( 2 points), meets mastery ( 3 points), and exceeds mastery (4 points). The total score for each student was the combination of his/her scores on the six test words, ranging from a minimum of 6 points to a maximum of 24 points. Inter-rater reliability was .99 for the pre-assessment and .96 for the post-assessment (Cohen's kappa).

\section{Results}

\subsection{Student Attitudes toward Reading in English}

The descriptive statistics of the pre-RAS and post-RAS scores for the IPBRA group and the control group are reported in Table 1 and Table 2. The IPBRA group's attitudes in three domains were all improved after 10 weeks of interactive picture-book read-aloud intervention. The increase of attitudes in the affective domain was the highest $(M D=1.18)$, followed by the cognitive domain $(M D=.72)$ and the behavioral domain $(M D=.33)$. Overall, the IPBRA group's general reading attitudes became more positive after 10 weeks of interactive picture-book read-aloud intervention. The responses of the control group in the three domains, however, remained almost unchanged as well as their overall reading attitudes.

Paired-samples $t$-tests for changes of reading attitudes by each group indicated that the IPBRA group showed significantly better reading attitudes in all three domains after the read-aloud intervention (affective: $t=-16.007$, $p=<.001$; behavioral: $t=-4.720, p=<.001$; cognitive: $t=-8.589, p=<.001$ ), whereas for the control group no significant differences were found in the three domains and the overall reading attitudes (affective: $t=-.700, p$ $=.490$; behavioral: $t=-.550, p=.587$; cognitive: $t=-1.574, p=.128$; overall: $t=-1.591, p=.124$ ). In other words, the interactive picture-book read-aloud approach led to significant improvement in the students' overall 
attitudes toward reading in English $(t=-15.532, p<.001)$. Moreover, an independent-samples $t$-test indicated that the difference in the overall reading attitudes between the IPBRA group and the control group on the pre-test of RAS was not significant $(t=-.064, p=.949)$, suggesting the two groups' attitudes toward reading in English were similar at the onset of the intervention. However, students in the IPBRA group made significant progress in overall reading attitudes than those in the control group following the 10 -week intervention period $(t=16.155, p$ $<.001)$.

Table 1. Descriptive statistics for the IPBRA group's and the control group's scores on the pre-RAS

\begin{tabular}{cccc}
\hline & & $\operatorname{IPBRA}$ Group $(n=29)$ & Control Group $(n=27)$ \\
\cline { 3 - 4 } & & Mean $($ Std $)$ & Mean $($ Std $)$ \\
\hline \multirow{2}{*}{ Pre- $R A S$} & Affective & $1.27(.41)$ & $1.29(.40)$ \\
& Behavioral & $1.16(.25)$ & $1.13(.18)$ \\
& Cognitive & $2.50(.34)$ & $2.52(.34)$ \\
& Overall & $4.93(.75)$ & $4.94(.67)$ \\
\hline
\end{tabular}

Table 2. Descriptive statistics for the IPBRA group's and the control group's scores on the post-RAS

\begin{tabular}{cccc}
\hline & & IPBRA Group $(n=29)$ & Control Group $(n=27)$ \\
\cline { 3 - 3 } & & Mean $($ Std $)$ & Mean $($ Std $)$ \\
\hline \multirow{2}{*}{ Post $-R A S$} & Affective & $2.45(.30)$ & $1.30(.34)$ \\
& Behavioral & $1.49(.25)$ & $1.14(.14)$ \\
& Cognitive & $3.22(.29)$ & $2.61(.35)$ \\
& Overall & $7.16(.38)$ & $5.06(.58)$ \\
\hline
\end{tabular}

\subsection{Student Word Inference Ability}

Table 3 displays the descriptive statistics for the IPBRA group's and the control group's scores on the pre-test and post-test of WIA. The IPBRA group's mean score was 8.28 points out of a possible 24 on the pre-assessment (range $=6-12)$. The group's mean score increased to 20.38 points on the post-assessment (range $=16-24)$. However, the mean score of the control group on the post-WIA remained almost unchanged (range $=6-13$ ), compared with that on the pre-WIA (range =6-14).

Two paired-samples $t$-tests for changes of word inference ability indicated that for the IPBRA group the mean difference between the pre-test and post-test of WIA was -12.10, a significant progress in their ability to use prior knowledge and context to infer the meanings of unknown words after the intervention $(t=-22.139, p<.001)$, but for the control group the mean difference $(M D=-.15)$ was not significant $(t=-.750, p=.460)$. An independent-samples $t$-test indicated that the difference in word inference ability between the IPBRA group and the control group on the pre-assessment was not significant $(t=-.167, p=.868)$. However, over a 10 -week intervention period, students in the IPBRA group made significant progress in word inference ability than those in the control group $(t=17.898, p<.001)$.

Table 3. Descriptive statistics for the IPBRA group's and the control group's scores on the pre- and post-WIA

\begin{tabular}{ccc}
\hline & $\operatorname{IPBRA}$ Group $(n=29)$ & Control Group $(n=27)$ \\
\cline { 2 - 3 } & Mean $($ Std $)$ & Mean $($ Std $)$ \\
\hline Pre-WIA & $8.28(2.02)$ & $8.37(2.22)$ \\
Post-WIA & $20.38(2.34)$ & $8.52(2.62)$ \\
\hline
\end{tabular}

\section{Discussion}

The present study showed that the interactive picture-book read-alouds had significant effects on cultivating middle school EFL students' word inference ability and attitudes toward reading in English. In line with previous research conducted with L1 learners using similar approaches (Goerss, Beck, \& McKeown, 1999; Marchessault \& Larwin, 2014), this study found that interactive read-alouds with teacher modeling and scaffolded practice had a positive impact on middle school students' use of prior knowledge and text to infer the meanings of unfamiliar words. The interactive whole-class talk about the text and unknown words, during which the teacher modeled the process of inferring a word's meaning, listened carefully to how students made sense of the story to determine a word's meaning, and then had students elaborate, clarify, or substantiate their analyses of the text and 
illustrations, provided the teacher with valuable information with which she could monitor each student's level of understanding and use of context. As Goerss et al. (1999) asserted, simply offering general guidelines for deriving word meanings from context or teaching certain types of context clues is insufficient. Students need guided practice in the complex operation of examining and selecting information from the context of unknown words and then pulling together the relevant information to guess at a word's meaning.

The improvement in reading attitudes identified in the current study, on the other hand, contradicts Hilbelink's (1998) study showing that a teacher's reading juvenile books aloud to eighth-grade students did not result in significant changes in their reading attitudes. This discrepancy may be due to three factors: the duration of the intervention, the reading material used, and the way teacher read-aloud was delivered. In Hilbelink's (1998) study, the intervention was implemented for only three weeks, and the teacher just simply read aloud from a children's novel to eighth graders without interactions, each time covered 10-20 pages. The duration of the intervention is crucial in influencing students' attitudes (Aguanta Jr. \& Tan, 2018). The period of treatment time, 3 weeks, might be too short to expect the participants to make sufficient increase in affective aspect of reading. It may take longer to see the treatment's effect on the participants' attitudes toward reading. In addition, picture books are easy to comprehend as compared with juvenile books. The feature of being profusely illustrated makes picture books attractive and interesting, helps English learners pick up the meanings of some hard words, and supports comprehension (Aikman, 1995; Fingerson \& Killeen, 2006), which accordingly boosts learners' reading confidence while lowering their affective filter and anxiety levels (Day \& Bamford, 1998). Unlike traditional lessons devoted to training students to derive word meanings from context using specific sets of clues or applying a prescriptive rule or strategy with a fixed sequence of steps, the IPBRA approach in the present study emphasized helping students engage with the teacher and peers in thoughtful analysis of text and illustrations to examine, identify, and obtain relevant information to create a reasonable meaning for an unfamiliar word while the primary focus of the discussion was on constructing meaning to build understanding of the text. Therefore, the emphasis of evaluation during read-alouds is not on a right answer, but on students' personal reactions to the stories and processes of merging their prior knowledge with text and illustration evidence to figure out the meaning of words that elude them. In other words, the IPBRA approach placed great emphasis on positive classroom environment, a source to forge positive attitudes toward reading (Day \& Bamford, 1998). The teacher's active engagement of students in making sense of the story through interactive read-alouds also propelled their processing of the information in the text and illustrations, motivated deeper thinking about the text, provided opportunities to verbalize and explain their thinking about the meaning of a word, and helped them confirm or revise their understanding as the story unfolded. This meaningful, personal involvement helped students engage thoroughly in active processing of information and further activated their willingness to learn as they became immersed in working with the teacher and peers to determine the logical meaning of a word in a particular context. Their mental investment in sharing with and learning from one another to construct meaning and discuss opinions was rewarded with deeper understanding and greater enjoyment, which naturally led them to become highly familiar with the word learning strategy and its use. The teacher-to-student and student-to-student interactions during reading aloud aroused reading interest and enhanced reading comprehension, which in turn made learning enjoyable and meaningful (Sun, 2020). Hence, students' favorable feelings for the reading materials and activities used in class and pleasant experiences with the teacher and classmates while learning can lead to positive attitudes toward reading (Day \& Bamford, 1998). It is commonly contended that positive reading attitudes lead to a greater likelihood of actively engaging in constructing meaning and, hence, to success in learning (McKenna, Kear, \& Ellsworth, 1995).

\section{Conclusions}

The current study investigated the effects of interactive picture-book read-alouds on middle school EFL students' attitudes toward reading in English and ability to infer the meanings of unfamiliar words from context and illustrations. The findings showed that this approach focusing on reading for meaning is a powerful way to increase EFL middle schoolers' reading attitudes and word inference ability. The motivating learning atmosphere of interactive picture-book read-alouds provided positive classroom environment and enabled learners to have fun while interacting freely with one another, which, in turn, facilitated reading attitude changes, leading to better learning and better performance on word inference in subsequent reading activities. This is not to argue against the value of reading alone for developing word inference ability but rather to point out that the interactive read-aloud approach focusing on motivating students to actively engage in meaning-construction processes is a better way to introduce them to the process and provide a firm foundation for independent development of inference ability. To promote the level of word learning prescribed in curriculum standards, it is suggested that middle school EFL teachers supplement textbook units and direct teaching of context aids by incorporating 
read-alouds with frequent informal discussions of picture books and use of context cues into their language teaching. Also, teacher read-alouds can introduce these older learners to picture books suited to their interests, maturity, and reading ability that they might not be able to locate on their own (Lesesne, 2001). To help students transfer what they learn in class during interactive read-alouds to their ordinary reading, English teachers should invite them to read more texts of a level sufficiently but not overly challenging and then encourage them to read more widely and often for pleasure.

\section{References}

Aguanta Jr., E. R. \& Tan, D. A. (2018). Effects of Dyad Cooperative Learning Strategy on Students' Academic Performance and Attitude towards Mathematics. International Journal of English and Education, 7(3), 303-313.

Aikman, C. C. (1995). Ideas in Practice: Picture Books and Developmental Students. Journal of Developmental Education, 19(1), 28-32.

Albright, L. K. \& Ariail, M. (2005). Tapping the Potential of Teacher Read-alouds in Middle Schools. Journal of Adolescent \& Adult Literacy, 48(7), 582-91. http://doi.org/10.1598/JAAL.48.7.4

Amer, A. A. (1997). The Effect of the Teacher's Reading Aloud on the Reading Comprehension of EFL Students. ELT Journal, 51(1), 43-47. http://doi.org/10.1093/elt/51.1.43

Ariail, M. \& Albright, L. K. (2005). A Survey of Teachers' Read-aloud Practices in Middle Schools. Reading Research and Instruction, 45(2), 69-89. http://doi.org/10.1080/19388070609558443

Artley, A. S. (1975). Good Teachers of Reading: Who Are They? The Reading Teacher, 29(1), 26-31.

Beers, K. (1998). Choosing Not to Read: Understanding Why Some Middle Schoolers Just Say No. In K. Beers \& B. G. Samuels (Eds.), Into Focus: Understanding and Creating Middle School Readers (pp. 37-63). MA: Christopher-Gordon Publishers.

Carnine, D., Kameenui, E. J. \& Coyle, G. (1984). Utilization of Contextual Information in Determining the Meaning of Unfamiliar Words. Reading Research Quarterly, 19(2), 188-204. http://doi.org/10.2307/747362

Chen, K. T. C. \& Chen, S. C. L. (2015). The Use of EFL Reading Strategies among High School Students in Taiwan. The Reading Matrix, 15(2), 156-166.

Chiang, M. H. (2016). Effects of Varying Text Difficulty Levels on Second Language (L2) Reading Attitudes and Reading Comprehension. Journal of Research in Reading, 39(4), 448-468. http://doi.org/10.1111/1467-9817.12049

Clark, S. K. \& Andreasen, L. (2014). Examining Sixth Grade Students' Reading Attitudes and Perceptions of Teacher Read Aloud: Are All Students on the Same Page? Literacy Research and Instruction, 53(2), 162-182. http://doi.org/10.1080/19388071.2013.870262

Day, R. R. \& Bamford, J. (1998). Extensive Reading in the Second Language Classroom. New York: Cambridge University Press.

Fingerson, J. \& Killeen, E. B. (2006). Picture Books for Young Adults. Teacher Librarian, 33(4), 32-34.

Goerss, B. L., Beck, I. L. \& McKeown, M. G. (1999). Increasing Remedial Students' Ability to Derive Word Meaning from Context. Reading Psychology, 20(2), 151-175. http://doi.org/10.1080/027027199278457

Harvey, S. \& Goudvis, A. (2017). Strategies That Work: Teaching Comprehension for Understanding and Engagement. Portland, ME: Stenhouse Publishers.

Hibbing, A. N. \& Rankin-Erickson, J. L. (2003). A Picture is Worth a Thousand Words: Using Visual Images to Improve Comprehension for Middle School Struggling Readers. The Reading Teacher, 56(8), 758-770.

Hickman, P., Pollard-Durodola, S. \& Vaughn, S. (2004). Storybook Reading: Improving Vocabulary and Comprehension for English-language Learners. The Reading Teacher, 57(8), 720-730.

Hilbelink, R. L. (1998). Read aloud effectiveness on comprehension and attitude in the junior high social studies classroom (Unpublished master's thesis). Dordt College, Iowa, U.S.A.

Hill, J. L. (2002). Playing with "The Three Pigs": Not Just for Children. Simulation \& Gaming, 33(3), 353-359. http://doi.org/10.1177/104687810203300309

Ivey, G. \& Broaddus, K. (2001). "Just Plain Reading”: A Survey of What Makes Students Want to Read in Middle School Classrooms. Reading Research Quarterly, 36(4), 350-377. 
http://doi.org/10.1598/RRQ.36.4.2

Johnson, D. (2002). Web Watch: Picture Book Read-alouds. Reading Online, 5(9). https://www.readingonline.org/electronic/elec_index.asp?HREF=webwatch/picturebooks/index.html

Kasza, K. (2003). My Lucky Day. New York: G. P. Putnam's Sons.

Khodabakhshi, S. C. \& Lagos, D. C. (1993). Reading Aloud: Children's Literature in College ESL Classes. The Journal of the Imagination in Language Leaning, 1, 52-55.

Lesesne, T. S. (2001). Timing: The Right Book at the Right Moment. Voices from the Middle, 9(1), 68-72.

Livaudais, M. F. (1985). A survey of secondary (grades 7-12) students' attitudes toward reading motivational activities (Unpublished doctoral dissertation). University of Houston-University Park, Texas, U.S.A.

Lyman, C. (2010). Reading aloud to middle school students to improve their attitudes about reading (Unpublished doctoral dissertation). The University of Mississippi, Mississippi, U.S.A.

Maloch, B. \& Beutel, D. D. (2009). "Big Loud Voice. You Have Important Things to Say": The Nature of Student Initiations during One Teacher's Interactive Read-alouds. Journal of Classroom Interaction, 44(2), 20-29.

Marchessault, J. K. \& Larwin, K. H. (2014). The Potential Impact of Structured Read-aloud on Middle School Reading Achievement. International Journal and Research in Education, 3(3), 187-196. http://doi.org/10.11591/ijere.v3i3.6463

McKenna, M. C., Conradi, K., Lawrence, C., Jang, B. G. \& Meyer, J. P. (2012). Reading Attitudes of Middle School Students: Results of a U.S. Survey. Reading Research Quarterly, 47(3), 283-306. http://doi.org/10.1002/rrq.021

McKenna, M. C., Kear, D. J. \& Ellsworth, R. A. (1995). Children's Attitudes toward Reading: A National Survey. Reading Research Quarterly, 30(4), 934-956. http://doi.org/10.2307/748205

MOE. (2008). Grade 1-9 Curriculum Guidelines of English Teaching and Learning. Retrieved from https://www.k12ea.gov.tw/ap/sid17_law.aspx

Nation, P. (2001). Learning Vocabulary in Another Language. Cambridge: Cambridge University Press.

Sanacore, J. (2000). Promoting the Lifetime Reading Habit in Middle School Students. The Clearing House, 73(3), 157-61. http://doi.org/10.1080/00098650009600937

Santos, J. A. (1987). The effects of teachers' reading aloud on the second language learner's reading comprehension, listening comprehension, and attitude towards reading (Unpublished doctoral dissertation). Boston University, Massachusetts, U.S.A.

Serravallo, J. (2015). The Reading Strategies Book: Your Everything Guide to Developing Skilled Readers. Portsmouth, NH: Heinemann.

Smallwood, B. A. (1992). Children's Literature for Adult ESL Literacy. (ERIC Document Reproduction Service No. ED353864).

Stahl, S. A. \& Nagy, W. E. (2005). Teaching Word Meanings. New York, NY: Routledge.

Stoller, F. L. \& Grabe, W. (1993). Implications for L2 Vocabulary Acquisition and Instruction from L1 Vocabulary Research. In H. Thomas, M. Haynes \& J. Coady (Eds.), Second Language Reading and Vocabulary Learning (pp. 24-44). Norwood, NJ: Ablex.

Sun, C. H. (2015). The Three Little Wolves Go to College: A Picture Book Lesson for Young Adult EFL Learners. Journal of Adolescent \& Adult Literacy, 59(2), 183-195. https://doi.org/10.1002/jaal.434

Sun, C. H. (2020). Interactive Picture Book Read-alouds to the Rescue: Developing Emerging College EFL Learners' Word Inference Ability. Journal of Adolescent \& Adult Literacy, 63(5), 509-517. https://doi.org/10.1002/jaal.1010

Trelease, J. (2006). The Read-aloud Handbook. Newbury Park, CA: Sage Publications.

Tullock-Rhody, R. \& Alexander, J. E. (1980). A Scale for Assessing Attitudes toward Reading in Secondary Schools. Journal of Reading, 23(7), 609-614.

Walters, J. (2004). Teaching the Use of Context to Infer Meaning: A Longitudinal Survey of L1 and L2 Vocabulary Research. Language Teaching, 37(4), 243-252. http://doi.org/10.1017/S0261444805002491 
Walters, J. (2006). Methods of Teaching Inferring Meaning from Context. RELC Journal, 37(2), 176-190. http://doi.org/10.1177/0033688206067427

Warren, C. L. (2012). Middle school students' reading experiences and behaviors and their relationship to reading achievement and self-efficacy: A study of one rural middle school in South Texas (Unpublished doctoral dissertation). Texas A\&M University - Corpus Christi, Texas, U.S.A.

Zambo, D. (2005). Using the Picture Book Thank You, Mr. Falker to Understand Struggling Readers. Journal of Adolescent \& Adult Literacy, 48(6), 502-512. http://doi.org/10.1598/JAAL.48.6.5

\section{Copyrights}

Copyright for this article is retained by the author(s), with first publication rights granted to the journal.

This is an open-access article distributed under the terms and conditions of the Creative Commons Attribution license (http://creativecommons.org/licenses/by/3.0/). 